\title{
Transformational Nursing Leadership Practices, Staff Retention and Promotion of Quality Healthcare Training: Evidence from Nursing Colleges in Ghana
}

\author{
Hannah Yawson, PhD Candidate \\ Principal, Twifo Praso Nurses \& Midwife Training College \\ Email: ber976@gmail.com
}

\begin{abstract}
This paper examined the dynamics of transformational leadership practices, staff retention and promotion of quality healthcare training. The study focused on nurses and midwives training colleges in Ghana. The paper employed quantitative analytical procedure and survey design. Questionnaire was used for the collecting the data. Multi-stage sampling technique was used which emphasised cluster and simple random sampling techniques. Sample size of 102 was used. 78 out of the 102 questionnaires were obtained and processed. Mean scale and standard multiple regression were employed for the analyses. The study revealed although the level of perceived transformational leadership practices is low, all the constructs exhibited significant positive effect on staff retention except Intellectual Stimulation (IS) which revealed insignificant positive effect. It was further found that although all the transformational leadership constructs exhibited positive effect, only Inspirational Motivation and Intellectual Stimulation (IS) are significant. However, when moderated by staff retention, all the transformational leadership constructs revealed significant and improved positive influence on perceived quality healthcare training. It is therefore recommended that policy in improving quality healthcare training should integrate both the promotion of transformational leadership and improved staff retention in nurses and midwives training colleges in Ghana.
\end{abstract}

Keywords: Transformational Leadership, Staff Retention, Promotion of Quality Healthcare Training, Principals DOI: $10.7176 / \mathrm{JBAH} / 12-4-03$

Publication date: February $28^{\text {th }} 2022$

\section{Introduction}

Leadership has become more important in todays' world of work. The endorsement and application of effective leadership style ensures changes in attitudes, values and behaviours through interactions between leaders and followers (Bass, \& Riggio 2006). In fact, leadership cannot be isolated in pursuing any successful endearvour and its value extends beyond pure managerial field to other fields including the healthcare sector. Leadership styles are vital to defining a healthcare facility's culture and provide a favorable environment that encourages freedom, motivation, job satisfaction, and career progress (Marquis \& Huston, 2017).

Several studies have demonstrated empirically that nursing profession is one of the stressful occupation in the health fraternity (Baglioni, Cooper, \& Hingley, 1990; Brown, \& Edelmann, 2000; Su, Boore, Jenkins, Liu. \& Yang, 2009). It has been documented that institutional factors such as leadership style can either drive the stress or contribute to the well-being of the staff (Arnetz, \& Blomkvist, 2007; Bartram, Joiner, \& Stanton, 2004; Lohela, Bjorklund, Vingard, Hagberg, \& Jensen, 2009). In fact, the concept of leadership in healthcare have historical undergone several developments, presenting different peculiarities over time and constantly changing environment (Institute of Medicine, 2004).

The stress and work related challenges have not only affceted quality of healthcare but also have triggered staff turnover. Studies have proved that there is increased levels of turnover among nurses coupled with fatigue negatively influence the work environment, increase the cost of healthcare, and hinder quality of care patients receive (Adams et al., 2019; Nasurdin et al., 2018; Kaddourah et al., 2018). For instant, the Bureau of Labor Statistics (2020) in United State has estimated that the number of registered nurses is expected to increase by $7 \%$, or 221,900 between 2019 and 2029, which currently outlined the high level of nurses turnover (Nasurdin et al., 2018). The situation is not different in African. Ghana has also documented hostile working environment in hospitals with sometimes outburst of demonstrations against leadership. For instance in 2017, nurses at Ankaful Psychiatric Hospital went on a sit-down strike due to inadequate funding and managerial issues with the head of the facility (Mordy, 2019).

The government responded through managerial training for heads of several hospitals. In effect, they are recognising the critical role of leadership in quality healthcare and staff turnover. An effective leadership could provide a favourable work environment that will create an equal opportunity for progress and satisfaction among staff members. Leadership style is a necessary function in shaping organizational performance in the area of job satisfaction that can ultimately improve patient care (Marquis \& Huston, 2017). Among the leadership qualities, transformational leadership is emerging as fundamental for followership well-being, productivity and continuity 
(Roux \& Hartel, 2018). Nurses managers and principals of nurses training institutions require leadership capable of transforming not only the physical environment, but also the beliefs and practices of nurses. Hence, transformational nursing leadership has been acknowledged as the suitable approach for dynamic evolving situation and learning to facilitate adoption (Bucic et al. 2010; Borkowski et al. 2011).

Transformational leaders display trutworthiness or engage with their followers inpursuit of jointly held goals (Antonakis, 2001; Barker, Sullivan \& Emery, 2006). In other word, transformational leadership is the relationship where leaders and followers raise one another to higher levels of motivation and morality. A transformation leader inspires others to develop, implement and encourages enthusiasm among the workers as well as recognised the values employees place on their work. These leaders also recognise areas in which change is needed and they guide and inspire their followers and creating a sense of commitment (Bucic et al. 2010; Borkowski et al. 2011). Thus, endorsement and application of this leadersip quality is funadmental in addressing the working challenges, productivity and turnover problem of nurses in the health fraternity (Asif, Jameel, Hussain, Hwang \& Sahito, 2019; Higgins, 2015; Magbity, 2018).

Despite the fact that the leadership challenges affect all nurses, a critical evaluation of the empirical literature show that the focus has been on nurses at hospitals with those in the health training institutions in neglect (Adzei \& Atinga, 2012; Asif, et al., 2019; Dawson, 2014; Eisler, 2009; Higgins, 2015; Kouzes \& Posners, 2001; Magbity, 2018). Extending the literature to the nurses and midwifery colleges is very critical as they are primary suppliers of the nurses who work in the health facilities. As the adage goes 'Garbage In, Garbage Out' Thus, paucity of literature on the dynamics of transformational leadership practices, staff retention and promotion of quality healthcare training could obscure the direction of policy in dealing with management and quality of training fundamentals in the health training institutions especially the Nurses and midwifery training colleges in Ghana.

The few studies in Ghana such as Adzei and Atinga (2012) focused on motivation and retention of health workers in Ghana's district hospitals. Magbity (2018) also focused on nurse managers' leadership styles and turnover intention among nurses in Brong Ahafo Region - Ghana. Despite the theoretical bases, virtually no study has considered the role of leadership in the quality of healthcare training and the interacting role of staff retention in the dynamics. With the new direction in tertiary education in Ghana, poor working conditions at these training institutions would not only affect promotion of quality of healthcare training negatively but also could push the staff to other institutions. It is against these that this paper seeks to explore the dynamics of principals' transformational leadership, staff turnover and promotion of quality healthcare training in nurses and midwives training colleges in Ghana. The rest of the paper is organised as follows: literature review and hypothesis development, empirical methodology, empirical estimation, empirical results and discussions.

\section{Literature Review and Hypothesis Development}

This study is grounded in the behavioural leadership theory. It is a management belief that assesses leaders by their engagements displayed at the workplace. Followers of the theory believe that to be an effective leader one has to learn a specific set of behaviors. If the individual is interested in becoming an efficient leader or in instigating a new leadership style, the person can benefit from studying behavioral leadership theory (Roux \& Hartel, 2018). Behavioural leadership theory argues that a leader's success is centered on their behaviour instead of their natural attributes. Behavioural leadership theory comprises evaluating and observing a leader's behaviours and actions when they are reacting to a particular situation (Rajbhandari, 2017). The theory considers that leaders are not borne, but made. Proponents of the theory posit that everybody can be an effective leader if the person can study and apply specific behaviours.

The theory supports the notion that all leaders are able to learn and develop by adopting helpful behaviours and execute them in the workplace (Roux \& Hartel, 2018). Behavioural leadership theory also inspires leaders to be self-aware of their behaviour and to identify how it impacts the morale and productivity of the team. There are numerous important behavioural leadership styles (Goff, 2003). Each style comprises a diverse set of behaviours and may be relatively effective in specific work environments. One identifiable leadership style which is believed to have positive effect on staff productivity and quality of services is transformational leadership. Transformational leaders labour with followers or team beyond the instant self-interests of the followers to identify desired change, constructing a vision to direct the change by inspiration, influence, and performing the change with dedicated group members; this self-interests change increases the followers' ideal and maturity levels, besides their trepidations for the accomplishment (Odumeru and Ogbonna, 2013). This leader influences followers and motivates the followers to work beyond the supposed capabilities. Transformational leadership motivates individuals to accomplish remarkable or unexpected results (Kwan, 2020).

Workers are provided with self-sufficiency above specific jobs, besides the ability to make decisions once training has been done. This encourages a positive change in the attitudes of followers and organization in general. Transformational leadership can be perceived when followers and leaders advance each other to an advanced motivation and morality level. By the strength of the personality and vision, transformational leaders are competent to encourage followers to change perceptions, motivations and expectations to work towards mutual goals. 
Followers have close bond and attachment to transformational leaders and would go extra mile to work with them. Following these theoretical considerations, by practicing transformational leadership in Nurses and Midwifery training colleges, principals would likely draw the staff along. Thus, principals' transformational leadership practice could enhance staff retention. The study therefore follows these assumptions and hypothesise as follows:

$H_{1}$ : Perceived principals' transformational leadership practices has significant positive influence on the level of readiness to stay (staff retention)

Moreover, transformational leaders labour with followers, influence their team to go beyond their desires to achieve performance goals (Odumeru and Ogbonna, 2013). According to Kwan (2020), a transformational leader motivates individuals to accomplish remarkable or unexpected results (Kwan, 2020). The theoretical implication is that leaders who exhibit transformational qualities are likely to achieve remarkable results. By extension, principals who endorse transformational qualities could also improve quality of healthcare training of students in their schools. The study follows these to formulate its second hypothesis as follows:

$\mathrm{H}_{2}$ : There is a significant positive relationship between perceived principals' transformational leadership practices and promotion of quality healthcare training

Since training is continuity, the quality of training may also be dependent on continuity. Transformational leadership can be perceived when followers and leaders advance each other to an advanced motivation and morality level. By the strength of the personality and vision, transformational leaders are competent to encourage followers to change perceptions, pursue continuity, motivations and expectations to work towards mutual goals. Marrying the critical role of transformational leadership practices to the need for continuity of services through staff retention, this study argues that staff retention could strengthen or weaken the strength of the relationship between perceived principals' transformational leadership practices and promotion of quality healthcare training. The study presents its third hypothesis as follows:

$\mathrm{H}_{3}$ : Staff retention has a significant moderating role on the prelationship between perceived principals' transformational leadership practices and promotion of quality healthcare training

Besides the theoretical discussions, some studies have been conducted in the empirical literature (Adzei \& Atinga, 2012; Asif, et al., 2019; Dawson, 2014; Eisler, 2009; Higgins, 2015; Kouzes \& Posners, 2001; Magbity, 2018). These studies have largely focused on hospitals which little emphasis place on health training institutions (Adzei \& Atinga, 2012; Asif, et al., 2019; Dawson, 2014; Eisler, 2009; Higgins, 2015; Kouzes \& Posners, 2001; Magbity, 2018) which are suppliers of the practitioners to the hospitals. As the adage goes 'Garbage In, Garbage Out' Thus, paucity of literature on the dynamics of transformational leadership practices, staff retention and promotion of quality healthcare training could obscure the direction of policy in dealing with management and quality of training fundamentals in the health training institutions especially the Nurses and midwifery training colleges in Ghana. The few studies in Ghana such as Adzei and Atinga (2012) focused on motivation and retention of health workers in Ghana's district hospitals. Magbity (2018) also focused on nurse managers' leadership styles and turnover intention among nurses in Brong Ahafo Region - Ghana. Despite the theoretical bases, virtually no study have considered the role of leadership in the quality of healthcare training and the interacting role of staff retention in the dynamics.

\subsection{Empirical Methodology}

The study employs quantitative approach and survey design as analytical techniques. The choice of quantitative approach is consistent with the literature which dictates that when the focus of a study is an inquiry that seeks to determine relationship between phenomena measured with higher order statistical procedures (Bryne, 2013; Creswell, 2013). This paper also seeks to investigate possible relationship among transformational leadership, staff retention and quality healthcare which justifies appropriateness of this analytical procedure. The survey design also complements this analytical procedure. The survey design involves the use of standardised questionnaires to produces in-depth data to establish baselines against which future comparisons can be made or analysed. Survey design is appropriate as the paper sought to explore data which are normally not unobservable such as staff opinion and perceptions about transformational leadership, staff retention and quality healthcare constructs (Fraenkel \& Wallen, 2001).

Staffs of public Nurses and Midwifery training colleges in Ghana are the target population for this study. Sample size of 102 is used for the study and selected through a multi-stage sampling technique. Two sampling techniques are employed in this multi-stage sampling where first cluster sampling applied to group the colleges in geographical areas and finally simple random to select the allocated samples.

The data are collected through questionnaire administration. All the variables are measured on a 5-point scale. 21 scale items are used to measure transformational leadership with four sub-constructs: Idealised Influence (II); Inspirational Motivation (IM); Intellectual Stimulation (IS) and Individual Consideration (IC). Staff retention (SR) is measured using 9 scale items and perceived quality healthcare training (QHT) is also measured with 11 scale items. 


\subsection{Empirical Estimation}

The paper uses mean scale and standard multiple regression to analyse the data. The mean scale is used to determine the level of the three variables on the scale of 1 to 5 with 2.9 as the cut-off mean and any score lower than this within the 'low region' and greater is within the 'high region' (Dess, Lumpkin \& McFarlin, 2005; Yeboah, 2011). Subsequent to determining the levels, the study employs the standard multiple regression to estimate the three hypotheses $\left(\mathrm{H}_{1}\right.$ to $\left.\mathrm{H}_{3}\right)$. The study also checks internal consistency and reliability of the instruments which are requirements for scale instruments.

To avoid spurious regression, the study check possible multicollinearity problem using both 'Tolerance Value (TV)' and 'Variance Inflation Factor (VIF)'. Tolerance value is the inverse value of VIF. The general threshold is that when the tolerance value is less than 0.1 and the VIF is not greater than 10 , then it is safe to assume that there is multicollinearity problem. To test the first hypothesis $\left(\mathrm{H}_{1}\right)$ which seeks to determine the significant effect of principals' transformational leadership practices on staff retention, the study presents the estimation model as follows:

$S R_{i}=\alpha_{i}+\beta_{1} I I_{i}+\beta_{2} I M_{i}+\beta_{3} I S_{i}+\beta_{4} I C_{i}+\beta_{5} A g e_{i}+\beta_{6} M S_{i}+\beta_{7} G e n_{i}+\beta_{8} W E_{i}+\beta_{9} L E_{i}+\varepsilon$

Where: SR is the dependent variable and denotes staff retention

II, IM, IS and IC are Idealised Influence (II); Inspirational Motivation (IM); Intellectual Stimulation (IS) and Individual Consideration (IC) are transformational leadership constructs and they serve as the independent variables.

Age, MS, Gen, WE and LE are vectors of control variables where MS denotes marital status, Gen is gender, WE denotes working experience and LE represents level of education $\varepsilon$ is the error term

$\beta_{1}, \beta_{2} \ldots \ldots \ldots \beta_{9}$ denote the sensitivities of SR to the respective variables. The magnitude and the level of significance determine the extent of the relationship between perceived principals' transformational leadership, and staff retention. The nature of the relationship is determined by the direction of $\beta_{1}$

It is expected that $\beta_{1}, \beta_{2} \ldots \ldots . . . \beta_{9}>0$

The second focus of the paper is to examine the dynamics of transformational leadership practices and perceived quality of healthcare training. Eqn(2) is used to test hypothesis $\left(\mathrm{H}_{2}\right)$ based on this nexus. The model is expressed as follows:

$Q H T_{i}=\alpha_{i}+\beta_{1} I I_{i}+\beta_{2} I M_{i}+\beta_{3} I S_{i}+\beta_{4} I C_{i}+\beta_{5} A g e_{i}+\beta_{6} M S_{i}+\beta_{7} G e n_{i}+\beta_{8} W E_{i}+\beta_{9} L E_{i}+\varepsilon$

Where: QHT is the dependent variable and denotes perceived promotion of quality healthcare

training

The rest of the variables remain as described in Eqn(1)

$\varepsilon$ is the error term

$\beta_{1}, \beta_{2} \ldots \ldots . . \beta_{9}$ denote the sensitivities of QHT to the respective variables. The magnitude and the level of significance determine the extent of the relationship between perceived principals' transformational leadership, and perceived quality healthcare training. The nature of the relationship is determined by the direction of $\beta_{1}$

It is expected that $\beta_{1}, \beta_{2} \ldots \ldots . . \beta_{9}>0$

The study further seeks to determine the extent to which staff retention could moderates the relationship between perceived principals' transformational leadership, and perceived quality healthcare training. The model for the estimation is specified in $\operatorname{Eqn}(3)$

$Q H T_{i}=\alpha_{i}+\beta_{1} I I_{i}^{* *}+\beta_{2} I M_{i}^{* *}+\beta_{3} I S_{i}^{* *}+\beta_{4} I C_{i}^{* *}+\beta_{5} S R_{i}+\beta_{6} A g e_{i}+\beta_{7} M S_{i}+\beta_{8} G e n_{i}+\beta_{9} W E_{i}+\beta_{10} L E_{i}+$ $\varepsilon(3)$

Where: The rest of the variables remain as described in Eqn(1) and Eqn(2)

$\varepsilon$ is the error term

$\beta_{1}, \beta_{2} \ldots \ldots . . \beta_{9}$ denote the sensitivities of QHT to the respective variables. The magnitude and the level of significance determine the extent at which staff retention moderates the relationship between perceived principals' transformational leadership, and perceived quality healthcare training. The nature of the relationship is determined by the direction of $\beta_{1}$

It is expected that $\beta_{1}, \beta_{2} \ldots \ldots . . \beta_{8}>0$

\subsection{Empirical Findings and Discussions}

Data properties and pre-diagnostics are presented and discussed prior to the empirical results. It is important to note that out of 102 samples, 78 was received and processed. This leads to response rate of $76.47 \%$. Table 1 presents the data characteristics of the respondents of the study. The results of the age distribution show that more than $73 \%(n=58,74.36 \%)$ of the participants are aged between $31-50$ years. Only $15.38 \%$ and $10.26 \%$ of the participants are aged below 30 years and above 50 years respectively. This implies that they are old and youthful to contribute meaningfully to this study. Majority of the respondents are married. About $61.54 \%$ of the respondents fall within this category. This suggests that these staff would need leadership support to commit to their jobs and 
engagement making transformational leadership analysis and staff retention crucial. It can also be found in Table 1 that majority $(n=43,55.13 \%)$. Females in Africa and Ghana for emphasis play dual roles: managing homes and demands of job. This family-work conflict could increase the stress of these female staff. Therefore, organisational support through sound leadership style is important for their retention decisions. Majority of the respondents have worked for 1 to 10 years $(n=58,74.36 \%)$. The youthful age coupled with the working experience implies that these staff have potential long service. More than half of the respondents have first degree as their highest qualification $(\mathrm{n}=49,62.82 \%)$.

Table 1: Demographic Factors of Respondents

\begin{tabular}{|c|c|c|c|}
\hline Variables & Freq. & $\%$ & Obs \\
\hline Age & & & 78 \\
\hline$<30$ Years & 12 & $15.38 \%$ & \\
\hline $31-40$ Years & 21 & $26.92 \%$ & \\
\hline 41-50 Years & 37 & $47.44 \%$ & \\
\hline$>50$ Years & 8 & $10.26 \%$ & \\
\hline Marital Status & & & 78 \\
\hline Single & 16 & $20.52 \%$ & \\
\hline Married & 48 & $61.54 \%$ & \\
\hline Divorced & 7 & $8.97 \%$ & \\
\hline Widowed & 0 & $0 \%$ & \\
\hline Co-Habitation & 7 & $8.97 \%$ & \\
\hline Gender & & & 78 \\
\hline Female & 43 & $55.13 \%$ & \\
\hline Male & 35 & $44.87 \%$ & \\
\hline Working Experience & & & 78 \\
\hline$<5$ Years & 23 & $29.49 \%$ & \\
\hline $6-10$ Years & 35 & $44.87 \%$ & \\
\hline $11-20$ Years & 11 & $14.10 \%$ & \\
\hline$>20$ Years & 9 & $11.54 \%$ & \\
\hline Level of Education & & & 78 \\
\hline First Degree & 49 & $62.82 \%$ & \\
\hline Second Degree & 29 & $37.18 \%$ & \\
\hline Third Degree & 0 & $0 \%$ & \\
\hline
\end{tabular}

\section{Source: Field survey, Yawson (2021)}

\subsubsection{Analysis of Internal Consistency and Reliability of the Scale}

The paper developed a 5-point scale to measure the three main variables: transformational leadership, staff retention and quality healthcare. Transformational leadership was measured with 21 scale items with four subconstructs: Idealised Influence (II); Inspirational Motivation (IM); Intellectual Stimulation (IS) and Individual Consideration (IC). Staff retention (SR) was measured using 9 scale items and quality healthcare (QHC) with 11 scale items. The reliability of these scales was based on the Cronbach alpha values. Following the literature interitem reliability is high when the alpha values are above the recommended threshold level of 0.60 (Meyers et al., 2013). The variables have Cronbach alph value range of 0.702 to 0.847 . This suggests that all the study variables have relatively high inter-item reliability (Meyers et al., 2013). This evidence further shows that there is relatively high convergent validity in the scales for the variables. It is therefore safe to conclude that there is high internal consistency of the data. 
Table 2: Reliability and Internal Consistency

\begin{tabular}{|c|c|c|}
\hline Variables & Item No. & Cronbach Alpha Value \\
\hline \multirow[t]{6}{*}{ II } & II1 & \\
\hline & II2 & \\
\hline & II3 & \\
\hline & II4 & \\
\hline & II5 & \\
\hline & II6 & 0.829 \\
\hline \multirow[t]{5}{*}{ IM } & IM1 & \\
\hline & IM2 & \\
\hline & IM3 & \\
\hline & IM4 & \\
\hline & IM5 & 0.798 \\
\hline \multirow[t]{5}{*}{ IS } & IS1 & \\
\hline & IS2 & \\
\hline & IS3 & \\
\hline & IS4 & \\
\hline & IS5 & 0.772 \\
\hline \multirow[t]{5}{*}{ IC } & $\mathrm{IC} 1$ & \\
\hline & IC2 & \\
\hline & IC3 & \\
\hline & IC4 & \\
\hline & IC5 & 0.702 \\
\hline \multirow[t]{9}{*}{ SR } & SR1 & \\
\hline & SR2 & \\
\hline & SR3 & \\
\hline & SR4 & \\
\hline & SR5 & \\
\hline & SR6 & \\
\hline & SR7 & \\
\hline & SR8 & \\
\hline & SR9 & 0.839 \\
\hline \multirow[t]{11}{*}{ QHC } & QHC1 & \\
\hline & QHC2 & \\
\hline & QHC3 & \\
\hline & QHC4 & \\
\hline & QHC5 & \\
\hline & QHC6 & \\
\hline & QHC7 & \\
\hline & QHC8 & \\
\hline & QHC9 & \\
\hline & QHC10 & \\
\hline & QHC11 & 0.847 \\
\hline
\end{tabular}

Source: Field survey, Yawson (2021)

Table 2: Reliability and Internal Consistency

\begin{tabular}{ccc}
\hline Variables & Item No. & Cronbach Alpha Value \\
\hline II & 6 & 0.829 \\
IM & 5 & 0.798 \\
IS & 5 & 0.772 \\
IC & 5 & 0.702 \\
SR & 9 & 0.839 \\
QHC & 11 & 0.847 \\
\hline
\end{tabular}

Source: Field survey, Yawson (2021)

\subsubsection{Descriptive Statistics}

The descriptive properties of the variables have been captured in Table 3 . The assessment was based on mean scale with 2.9 as the mean point or cut-off point and scores less than 2.9 are within the low region and above 2.9 are high region (Dess et al, 2005; Yeboah, 2011). It can be observed from the descriptive statistics that all the transformational leadership scores are within the 'Low Region' as none of them crosses the cut-off point of 2.9. 
The range for transformational leadership is 2.351 to 2.572 with Inspirational Motivation (IM) and Intellectual Stimulation (IS) exhibiting minimum and maximum mean values respectively. This implies that there is low transformational leadership practices in the nurses and midwifery training school in Ghana. The associated standard deviations are very low suggesting that the individual observations are closely packed around the mean. This collaborates with the coefficient of variations $(\mathrm{CoV})$. The CoVs are in the range of $4.4 \%$ to $8.2 \%$ suggesting that the observations are closely packed as the deviation is than $4.4 \%$ to $8.2 \%$.

The respondents generally want to stay in the profession as evident by the mean score within the 'High Region' $(\mathrm{m}=3.154, \mathrm{SD}=0.230)$. Although the level of staff retention is relatively high, its mean score did not meet the study expectation. Given the uniqueness of the profession with no direct alternative, the study expected the score to be more than 4.0. The standard deviation is very low and the coefficient of variation is just $7.3 \%$. This implies that there is strong similarity in the respondents' responses. The respondents generally believe that the level of quality health care is high $(\mathrm{m}=3.342, \mathrm{SD}=0.226)$. This response is not consistent with the study expectation as the mean score less than expected.

Table 3: Descriptive Statistics of Variables of Interest

\begin{tabular}{lllll}
\hline Variables & Mean & SD & CoV $^{*}$ & Obs. \\
\hline II & 2.532 & 0.152 & 0.060 & 78 \\
IM & 2.351 & 0.104 & 0.044 & 78 \\
IS & 2.572 & 0.211 & 0.082 & 78 \\
IC & 2.478 & 0.185 & 0.075 & 78 \\
SR & 3.154 & 0.230 & 0.073 & 78 \\
QHC & 3.341 & 0.226 & 0.068 & 78 \\
\hline
\end{tabular}

*CoV denotes coefficient of variation

Source: Field survey, Yawson (2021)

\subsubsection{Empirical Results of Transformational Leadership Practices and Staff Retention}

The study interrogates how the level of transformational leadership practices in the nurses and midwives colleges in Ghana could enhance staff retention. The staff retention is operationalised as the response variable or the criterion while the transformational leadership constructs are the independent variables or the regressors. The study also introduced respondents' demographic factors as control variables. The study first checks for multicollinearity problem. Using SPSS, the study employed 'Tolerance Value and Variance Inflation Factor (VIF)' to check multicollinaerity problem. Tolerance value is the inverse value of VIF. The general threshold is that when the tolerance value is less than 0.1 and the VIF is not greater than 10 , then it is safe to assume that there is multicollinearity problem. The results are captured in Table 4 . It can be seen from Table 4 that all the study variables have VIF values less than 10 and tolerance values of greater than 0.1 . This suggests that the model has not violated the multicollinearity assumption

Table 4: Multicollinearity Analysis

\begin{tabular}{llll}
\hline Study Variables & Tolerance Value & VIF & Decision \\
\hline II* $^{*}$ & .447 & 2.235 & No \\
IM $^{*}$ & .330 & 3.034 & No \\
IS $^{*}$ & .365 & 2.742 & No \\
IC & .311 & 3.212 & No \\
\hline
\end{tabular}

*Note: II denotes Idealised Influence, IM denotes Inspirational Motivation, IS represents Intellectual Stimulation, and IC is Individual Consideration

Source: Yawson (2021), Field Survey

Having confirmed that there is no multicollinearity problem, the study proceeds to estimate the model. The results are reported in Table 5. The $\mathrm{R}^{2}$ (adjusted $\mathrm{R}^{2}$ ) and the f-statistics are $0.722(0.705)$ and 38.067(0.000) respectively. The adjusted $\mathrm{R}^{2}$ is in the parenthesis of the $\mathrm{R}^{2}$. This implies that the regressors and the control variables explain about $72.2 \%$ of the variations in staff retention. This is very high. Moreover, the significant Fstatistics depict joint significance of all the regressors. Thus, even though some of the regressors may be not be significant independently but become relevant when they are jointly considered and analysed.

It can be observed from Table 5 that all the four constructs of transformational leadership are exhibiting positive effect on staff retention. Except intellectual stimulation (IS) which exhibit positive but insignificant influence, all the other transformational leadership constructs has significant positive influence on the staff retention. This implies that although the level of transformational leadership practices is low, the practice has significant positive on staff decision to stay. It is therefore critical to train and cause leadership in the nurses and midwifery training colleges to adopt and practice transformational leadership. The findings partly support and partly inconsistent with the study expectation as not all the transformational constructs exhibited significant positive influence. The findings however collaborate with some earlier findings suggesting a link between leadership and staff retention (Adzei \& Atinga, 2012; Eisler, 2009)

It can also be found that when staffs are aging, they prefer to stay in the profession with young ones likely to 
leave. This makes the need to resource leadership to adopt transformational leadership style very crucial. The youthful age is the class required to sustain quality of services. Unfortunately, this group is more likely to leave the profession. Staff with many years of experience, staff who are married and females are more likely to stay in the profession even though only working experience is significant. Surprisingly, staffs in the colleges with high level of education are more likely to leave. Though surprisingly, the finding may be associated with the fact that higher education would open up alternative opportunities including teaching in other higher education institutions.

Table 5: Empirical Results of Transformational Leadership and Staff Retention Nexus

\begin{tabular}{lccccl}
\hline & Beta & t-stat & Sig. & $\mathbf{R}^{2}$ & f-stat \\
\hline Model & & & & $0.722(0.705)$ & $38.067(0.000)$ \\
II & 0.0249 & 1.569 & 0.099 & & \\
IM & 0.1933 & 2.751 & 0.063 & & \\
IS & 0.0986 & 1.387 & 0.102 & & \\
IC & 0.0982 & 2.392 & 0.084 & & \\
Age & 0.1652 & 1.988 & 0.086 & & \\
Marital Status & 0.0321 & 1.276 & 0.114 & & \\
Gender & 0.1322 & 1.312 & 0.129 & & \\
Working Experience & 0.0431 & 1.564 & 0.098 & & \\
Level of Education & -0.1390 & -2.987 & 0.010 & & \\
\hline
\end{tabular}

Source: Field survey, Yawson (2021)

\subsubsection{Empirical Results of Transformational Leadership Practices and Quality Healthcare}

The study further analysed the relevance of transformational leadership practices by determining it implications on the promotion of quality healthcare. This addresses the second hypothesis of this paper. Similar to the model estimated earlier, the investigation includes control variables. Table 5 reveals $\mathrm{R}^{2}$, adjusted $\mathrm{R}^{2}$ of and the f-statistics are $0.631(0.612)$ and $26.426(0.001)$ respectively. The adjusted $R^{2}$ is in the parenthesis. This means that transformational leadership practices could explain about $63.1 \%(61.2 \%)$ of variation in the level of quality healthcare. This predictive power is very high suggesting that the model is sound. The F-statistics is significant. The significant f-statistics show joint significance of all the coefficients of the regressors. This implies that although some of the regressors may not be significant independently but become relevant when they are jointly considered and analysed.

Table 6 reports the coefficient $(\beta)$ of the individual constructs of principals' transformational leadership and the control variables. The findings reveal that although all the constructs of transformational leadership exhibit positive effect, only Inspirational Motivation and Intellectual Stimulation (IS) are significant. Idealised influence (II) had insignificant positive coefficient $(\beta=0.1002 ; p=.132)$ and individual consideration also had insignificant positive coefficient $(\beta=0.1191 ; p=.108)$. Despite these insignificant coefficients, Inspirational motivation (IM) also had significant positive influence on the level of quality healthcare $(\beta=0.2241 ; p=.027)$. Similarly, intellectual stimulation (IS) also showed significant positive effect on quality healthcare $(\beta=0.1270 ;$ Sig. $=.073)$.

The findings support the behavioural leadership theory. Consistent with the behavioural leadership theory, the study revealed that leaders who exhibit transformational qualities are likely to achieve remarkable results as evident in positive effect of transformational laedersip practices and quality healthcare training (Kwan, 2020; Odumeru \& Ogbonna, 2013). Some of the coefficients were not significant which may be attributed to the low level of perceived practice of transformational leadership qualities. Empirically, the results affirm the findings of Asif, et al (2019), Higgins (2015) and Manning (2014). For brevity, the control variables are not discussed except that they are exhibit positive effect on quality healthcare other than marital status.

Table 6: Empirical Results of Transformational Leadership and Quality Healthcare Nexus

\begin{tabular}{|c|c|c|c|c|c|}
\hline 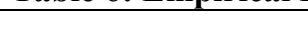 & Beta & t-stat & Sig. & $\mathbf{R}^{2}$ & f-stat \\
\hline Model & & & & $0.631(0.612)$ & $26.426(0.001)$ \\
\hline II & 0.1002 & 1.343 & 0.132 & & \\
\hline $\mathrm{IM}$ & 0.2241 & 4.262 & 0.027 & & \\
\hline IS & 0.1270 & 1.773 & 0.073 & & \\
\hline IC & 0.1191 & 1.432 & 0.108 & & \\
\hline Age & 0.0775 & 1.225 & 0.138 & & \\
\hline Marital Status & -0.0821 & 1.233 & 0.125 & & \\
\hline Gender & 0.0212 & 1.274 & 0.201 & & \\
\hline Working Experience & 0.1314 & 1.669 & 0.082 & & \\
\hline Level of Education & 0.3312 & 4.089 & 0.019 & & \\
\hline
\end{tabular}

Source: Field survey, Yawson (2021) 


\subsubsection{Moderating Role of Staff Retention on the Effect of Principal Transformational Leadership on Quality Healthcare}

The paper proceeds to determine the moderating role of staff retention on the effect of the principal's transformational leadership on quality healthcare as hypothesized in hypothesis 3 . Table 7 shows the results of this analysis. It can be observed from Table 7 that the $\mathrm{R}^{2}$, adjusted of $\mathrm{R}^{2}$ and the f-statistics are high. These show fitness of the model. It could be observed from the table that the $\mathrm{R}^{2}$ and adjusted $\mathrm{R}^{2}$ of the model are 0.7889 and 0.7640 respectively. This suggests that by introducing staff retention as a moderator, principal transformational leadership constructs explain $78.89 \%(76.40 \%)$ of variations in the level of quality healthcare with the adjusted $\mathrm{R}^{2}$ in the parenthesis. This means the moderator has increased the predictive powers of principal transformational leadership constructs as these explanatory scores are more than the original $\mathrm{R}^{2}$ and adjusted $\mathrm{R}^{2}$ statistics. Table 7 reveals $\mathrm{f}$ statistics of $42.116(0.000)$ from the estimation. The statistics inside the parentheses are the p-values of the f-stats. This $\mathrm{p}$-value is less than $1 \%$ suggesting that the f-stats found in the estimation are significant at $1 \%$. The implication is that even if the individual constructs are not significant, they are jointly significant when employed collectively in explaining the level of quality healthcare.

It can also be seen from Table 7 that all the individual constructs of principals' transformational leadership as moderated by staff retention are significant. The findings show that all the principals' transformational leadership moderated by staff retention has significant effect on the level of quality healthcare. Idealised influence as moderated by staff retention (II**) had significant coefficients $(\beta=0.3155 ; p=.029)$. Inspirational motivation as moderated by staff retention (IM**) also had significant positive influence on the level of quality healthcare $(\beta$ $=0.4263 ; \mathrm{p}=.006$ ). Similarly, intellectual stimulation moderated by staff retention (IS $* *$ ) also showed significant positive effect on quality healthcare $(\beta=0.3782$; Sig. $=.008)$ and individual consideration moderated by staff retention also had significant positive coefficient $(\beta=0.2978 ; p=.021)$. Staff retention also showed significant positive coefficient $(\beta=0.3021 ; p=.007)$. For brevity, the control variables are not discussed.

The significant coefficients revealed in Table 7 suggest that the study rejects all the null hypotheses that principals' transformational leadership constructs moderated by staff retention do not have a significant effect on the level of quality healthcare. It is therefore concluded that all the transformational leadership constructs moderated by staff retention have a significant influence on the level of quality healthcare. The findings imply that an increase in the level of idealised influence (II**), Inspirational motivation (IM**), intellectual stimulation (IS**) and individual consideration (IC**) would lead to $0.3155,0.4263,0.3782$ and 0.2978 points increase in the level of quality healthcare respectively and vice-versa. Thus, the level of idealised influence, intellectual stimulation, inspirational motivation and individual consideration as moderated by staff retention are desirable antecedents of perceived quality healthcare. Staff retention, the moderator would lead to 0.3021 increase in the level of perceived quality healthcare.

Overall, the findings suggest that improving staff retention coupled with practice of transformational leadership in nurses and midwifery training colleges in Ghana would significantly promote an improve quality healthcare training. This also supports some of the earlier studies (see Asif et al, 2019; Higgins, 2015).

Table 7: Estimation Moderating Role of Staff Retention on Principal's Transformational Leadership and Quality Healthcare Nexus

\begin{tabular}{|c|c|c|c|c|c|}
\hline & Beta & t-stat & Sig. & $\mathbf{R}^{2}$ & f-stat \\
\hline Model & & & & $0.7889(0.7640)$ & $42.116(0.000)$ \\
\hline $\mathrm{II} * *$ & 0.3155 & 3.986 & 0.029 & & \\
\hline $\mathrm{IM}^{* *}$ & 0.4263 & 5.743 & 0.006 & & \\
\hline IS** & 0.3782 & 4.834 & 0.008 & & \\
\hline $\mathrm{IC}^{* *}$ & 0.2978 & 4.015 & 0.021 & & \\
\hline SR & 0.3021 & 5.022 & 0.007 & & \\
\hline Age & 0.0986 & 1.658 & 0.048 & & \\
\hline Marital Status & 0.1010 & 1.533 & 0.085 & & \\
\hline Gender & 0.0567 & 1.632 & 0.060 & & \\
\hline Working Experience & 0.1210 & 2.098 & 0.037 & & \\
\hline Level of Education & 0.2212 & 3.689 & 0.031 & & \\
\hline
\end{tabular}

Note: $* *$ denote individual transformational leadership constructs moderated by staff retention

Source: Field survey, Yawson (2021)

\subsection{Conclusions and Implications}

This paper examined the dynamics of transformational leadership practices, staff retention and promotion of quality healthcare training. The study focused on nurses and midwives training colleges in Ghana. This study was conceived from the fact that although leadership has been identified as fundamental for effective work engagement and productivity of nurses, most of the studies have concentrated on only the hospitals neglecting the health training institutions. The paper employed quantitative analytical procedure and survey design. Questionnaire was 
used for the collecting the data. Multi-stage sampling technique was used which emphasised cluster and simple random sampling techniques. Mean scale and standard multiple regression were employed for the analyses.

The study revealed although the level of perceived transformational leadership practices is low, all the constructs exhibited significant positive effect on staff retention except Intellectual Stimulation (IS) which revealed insignificant positive effect. It was further found that although all the transformational leadership constructs exhibited positive effect, only Inspirational Motivation and Intellectual Stimulation (IS) are significant. However, when moderated by staff retention, all the transformational leadership constructs revealed significant and improved positive influence on perceived quality healthcare training. It is therefore recommended that policy in improving quality healthcare training should integrate both the promotion of transformational leadership and improved staff retention in nurses and midwives training colleges in Ghana.

The findings imply that transformational leadership practices are antecedents of improved staff retention. This suggests that policy makers could promote the practice of transformational leadership among principals in nurses and midwifery training colleges to relieve stresses and deepen retention rate. Additionally, the practice of transformational leadership within staff support to improve continuity (staff retention) could also improve and promote quality healthcare training. It is therefore recommended that policy in improving quality healthcare training should integrate both the promotion of transformational leadership and improved staff retention in nurses and midwives training colleges in Ghana.

\section{References}

Adams, A. M. N., Chamberlain, D., \& Giles, T. M. (2019). Understanding how nurse managers see their role in supporting ICU nurse well - being-A case study. Journal of nursing management, 27(7), 1512-1521.

Adzei, F. A., \& Atinga, R. A. (2012). Motivation and retention of health workers in Ghana's district hospitals: addressing the critical issues. Journal of health organization and management.

Arnetz, B, \& Blomkvist, V. (2007) Leadership, mental health, and organizational efficacy in health care organizations. Psychosocial predictors of healthy organizational development based on prospective data from four different organizations. Psychother Psychosom. 2007;76(4):242-8

Asif, M., Jameel, A., Hussain, A., Hwang, J., \& Sahito, N. (2019). Linking transformational leadership with nurseassessed adverse patient outcomes and the quality of care: assessing the role of job satisfaction and structural empowerment. International journal of environmental research and public health, 16(13), 2381.

Baglioni Jr A. J, Cooper, C. L, \& Hingley, P (1990). Job stress, mental health and job satisfaction among UK senior nurses. Stress Med. 1990;6(1):9-20.

Barker, A. M., Sullivan, D. T., \& Emery, M. J. (2006). Leadership competencies for clinical managers: The renaissance of transformational leadership. Jones \& Bartlett Learning.

Bartram, T, Joiner, T. A, \& Stanton, P (2004). Factors affecting the job stress and job satisfaction of Australian nurses: implications for recruitment and retention. Contemp Nurse. 17(3):293-304.

Bass, B. M., \& Riggio, R. E. (2006). Transformational leadership.

Borkowski, N., Deckard, G., Weber, M., Padron, L. A., \& Luongo, S. (2011). Leadership development initiatives underlie individual and system performance in a US public healthcare delivery system. Leadership in health services.

Brown, H, \& Edelmann, R. (2000) Project 2000: a study of expected and experienced stressors and support reported by students and qualified nurses. $J$ Adv Nurs. 2000;31(4):857-64.

Bucic, T., Robinson, L., \& Ramburuth, P. (2010). Effects of leadership style on team learning. Journal of Workplace learning.

Dawson, D. (2014). Essential principles: tracheostomy care in the adult patient. Nursing in critical care, 19(2), $63-72$.

Eisler, K. (2009). The leadership practices of nurse managers and the association with nursing staff retention and the promotion of quality care in two Saskatchewan hospitals. University of Toronto.

Goff, D. G. (2003). What Do We Know about Good Community College Leaders: A Study in Leadership Trait Theory and Behavioral Leadership Theory.

Higgins, E. A. (2015). The influence of nurse manager transformational leadership on nurse and patient outcomes: Mediating effects of supportive practice environments, organizational citizenship behaviours, patient safety culture and nurse job satisfaction.

Institute of Medicine. (2004). Keeping patients safe: Transforming the work environment of nurses. Washington, DC: National Academics Press.

Kaddourah, B., Abu-Shaheen, A. K., \& Al-Tannir, M. (2018). Quality of nursing work life and turnover intention among nurses of tertiary care hospitals in Riyadh: a cross-sectional survey. BMC nursing, 17(1), 1-7.

Kwan, P. (2020). Is transformational leadership theory passé? Revisiting the integrative effect of instructional leadership and transformational leadership on student outcomes. Educational Administration Quarterly, 56(2), 321-349. 
Lohela, M, Bjorklund, C, Vingard, E, Hagberg, J, \& Jensen, I (2009). Does a change in psychosocial work factors lead to a change in employee health? J Occup Environ Med. 51(2):195-203.

Magbity, J. B. (2018). Nurse Managers' Leadership Styles and Turnover Intention Among Nurses in Brong Ahafo Region-Ghana (Doctoral dissertation, University of Ghana).

Meyer, J. P., Stanley, L. J., \& Vandenberg, R. J. (2013). A person-centered approach to the study of commitment. Human Resource Management Review, 23(2), 190-202.

Nasurdin, A. M., Ling, T. C., \& Khan, S. N. (2018). The relation between turnover intention, high performance work practices (hpwps), and organisational commitment: a study among private hospital nurses in malaysia. Asian Academy of Management Journal, 23(1).

Odumeru, J. A., \& Ogbonna, I. G. (2013). Transformational vs. transactional leadership theories: Evidence in literature. International review of management and business research, 2(2), 355.

Rajbhandari, M. M. S. (2017). Leadership Actions-Oriented Behavioral Style to Accommodate Change and Development in Schools. SAGE Open, 7(4), 2158244017736798.

Roux, M., \& Härtel, C. E. (2018). The cognitive, emotional, and behavioral qualities required for leadership assessment and development in the new world of work. In Individual, Relational, and Contextual Dynamics of Emotions. Emerald Publishing Limited.

Su S-F, Boore, J, Jenkins, M, Liu. P,E, \& Yang, M, J (2009). Nurses' perceptions of environmental pressures in relation to their occupational stress. J Clin Nurs.2009;18(22):3172-80. 